\title{
Methods for Assessing Energy Efficiency of Buildings
}

\author{
Eduardo G. Serra ${ }^{* 1}$, Zander R. P. Filho ${ }^{2}$ \\ ${ }^{1}$ Environmental Engineering Program, Polytechnic School, Rio de Janeiro Federal University, \\ Av. Pedro Calmon, 550, Cidade Universitária, Rio de Janeiro, Brazil \\ e-mail: serra@poli.ufrj.br \\ ${ }^{2}$ Faculty of Architecture and Urbanism, Federal Fluminense Institute, Rua Miguel de Frias, 9, \\ Icaraí, Niterói, Rio de Janeiro, Brazil \\ e-mail: zander.filho@iff.edu.br
}

Cite as: Serra, E. G., Filho, Z. R. P., Methods for Assessing Energy Efficiency of Buildings, J. sustain. dev. energy water environ. syst., 7(3), pp 432-443, 2019, DOI: https://doi.org/10.13044/j.sdewes.d6.0243

\begin{abstract}
This article analyzes the case of a Brazilian Institute of Higher Education, in relation to compliance with a normative instruction, according to which all federal public buildings must follow the rules of energy efficiency. The aim of this work is to demonstrate the potential of Building Information Modeling to optimize the execution of reference instructions. As a case study, the energy efficiency of one of the Institute buildings was observed using the conventional method and a new method. Subsequently, a comparative analysis was carried out to indicate the most appropriate procedure for the Institute. Finally, it was observed that the new method showed an approximately $85 \%$ reduction in classification time due to its better performance in obtaining architectural design information and, if incorporated in the routine of the project, will contribute more adequately to the interests of the Institute.
\end{abstract}

\section{KEYWORDS}

Energy efficiency, Building information modeling, Federal fluminense institute, National energy efficiency program, National energy conservation label, Architectural design.

\section{INTRODUCTION}

The search for more energy efficient buildings and the new technological demands require projects that are increasingly complex and in an increasingly shorter space of time. According to Bay [1], the best opportunities to optimize the energy performance of a building occur at the beginning of the design process. However, Venâncio [2] recognizes the lack of materials and methods to support the architecture project in order to better use energy consumption. In conformity with Burberry [3], designers should familiarize themselves with the principles and methods of "thermal design" by applying them as part of the normal design procedure. However, Lima [4] states that the use of computational simulation turned to the analysis of energy efficiency still faces the lack of methods integrated to the nature of the architectural project. In Brazil, these methods have not been much used and there is not much academic work on them [5].

\footnotetext{
* Corresponding author
} 
Considering the importance of the integration of energy efficiency indices with the architecture project development, as Clarke [6] points out, new technologies to support this project need to be adopted [7]. Thus, Building Information Modeling (BIM) presents itself as a potential tool for the solution of these obstacles, since its concept has technological tools to organize and manage the information used [8], covering the entire life cycle of a building [9].

According to the american committee of the National Institute of Building Sciences (NIBS) [10], the BIM concept allows the integration of the various areas of the project, with all the building physical and functional information, linked to a model that collaborates to reduce environmental damage [11], increasing the building's functional performance [12]. For Azhar [13], BIM is a design and documentation methodology that makes the construction process easier and faster, improving the production chain for all involved.

Given this scenario, the Brazilian Federal Government published in 2014 the Normative Instruction No. 2/2014 [14], which requires the use of the National Classification of Energy Conservation (ENCE) class " $A$ " in the designs and respective new federal public buildings or in any remodeling that changes the lighting systems, air conditioning or the envelope of the building. This label is based on the Technical Quality Regulation (RTQ-C) for the Energy Efficiency Level of Commercial, Services and Public Buildings, containing the prescriptive method to evaluate buildings through analytical procedures and the computational simulation method, through specialized software. These methods are based on the information obtained in the architecture project and classify the building from concept "A" (most efficient) to "E" (least efficient) [15].

In this sense, the Fluminense Federal Institute (IFF), located in the city of Campos dos Goytacazes, in the State of Rio de Janeiro, is recognized for the quality of its infrastructure and architecture of its buildings. In the last decade, the institution has expanded in several sectors of activities. This fact implies the need to increase the constructed spaces [16]. Figure 1 shows the evolution of the constructed area and the increase in the electric demand between 2007 and 2015, requiring more efficient actions from this point of view as described in the Institutional Development Plan [17].
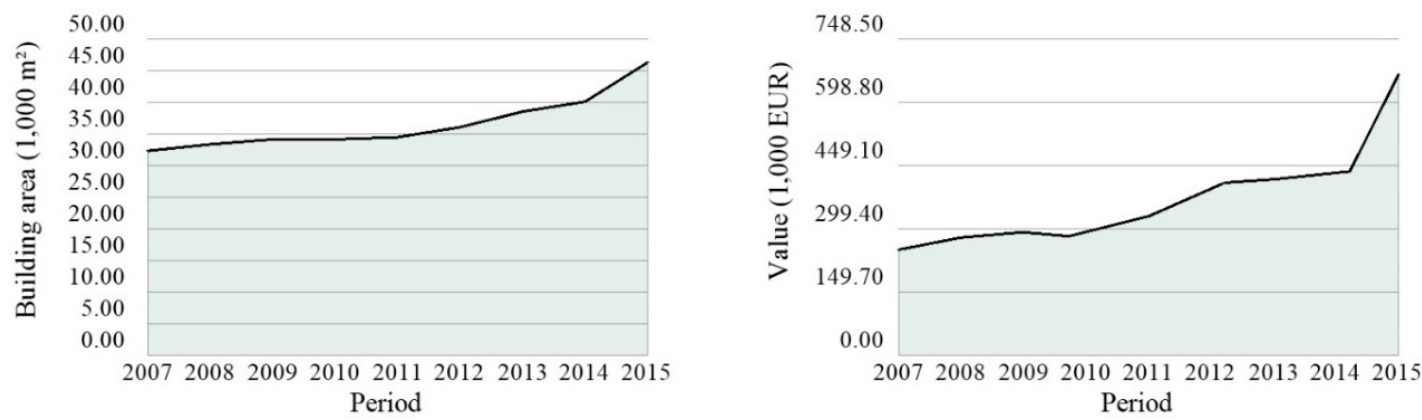

Figure 1. Analysis of the physical expansion and cost of electric power of the Federal Fluminense Institute between 2007 and 2015

For Lamberts [18], the use of unlimited natural resources, such as natural light, will increasingly become a prerequisite for the implementation of buildings, ensuring greater comfort and energy efficiency. In this perspective, a new building still under construction, denominated "Block G", deserves a prominent role for its strategic importance in the development of the institution.

In view of this, the hypothesis of this work is that the use of BIM incorporated into the routine of the Institute's projects will substantially facilitate the compliance of said normative instruction in its buildings and also identify aspects that may contribute to a more efficient architectural practice in this specific area. The aim of this article is to 
perform a comparative analysis of the results obtained between the method currently used by the institution's project sector and a new method proposed in this work, in order to determine which of the methods cited is the most appropriate to the Institute.

\section{METHODS}

In this study, the envelope of the new Institute building was classified separately by the prescriptive method and determined by a set of information obtained in the architecture project, divided into requirements and prerequisites, as shown in Figure 2.

Collection of envelope data
Requirements: Building Projection Area $\left(A_{\text {pe }}\right)$; Total Building Area $\left(A_{\text {tot }}\right)$; Envelope Area $\left(A_{\text {env }}\right)$; Vertical Shading
Angle $(A V S)$; Horizontal Shading Angle $(A H S)$; Form Factor $(F F)$; Height Factor $(F A)$; Solar Factor $(F S)$; Percentage
of opening in the total facade $\left(P A F_{\mathrm{t}}\right)$; Percentage of opening on the west facade $\left(P A F_{\mathrm{o}}\right)$; Total Building Volume
$\left(V_{\text {tot }}\right)$ and Bioclimatic $Z$ Zone $(\mathrm{ZB})$.
Prerequisites: Thermal transmittance of coverage of conditioned environments $\left(U_{\text {cob-ac }}\right)$; Thermal transmittance of
coverage of unconditioned environments $\left(U_{\text {cob-anc }}\right)$; Thermal transmittance of walls $\left(U_{\text {par }}\right)$; Solar coverage
absorptance $\left(A_{\text {cob }}\right)$ and Solar wall absorptance $\left(A_{\text {par }}\right)$.

Figure 2. Evaluation scheme by the prescriptive method

The verification of the hypothesis consisted of the elaboration of comparative criteria between the conventional method of classifying energy efficiency and the BIM method. The criteria to be analyzed and compared were divided into three distinct blocks:

- Interface: It aims to analyze the environment where the user (architect or designer) can communicate with the program, enter and manipulate data, and where commands and tools are available;

- Information management: It intends to investigate the flow of information generated in the architectural design and the aspects involved in the analysis of design solutions that can support the decision making process;

- Time: It will measure the time spent for classification using the conventional method and the proposed method.

\section{Study object}

The object of study of the research is the Block G Building (Figure 3) located in Bioclimatic Zone 5 [19]. Its choice was given, especially, because it is the construction of greater dimension and importance in the strategic planning of the institution.
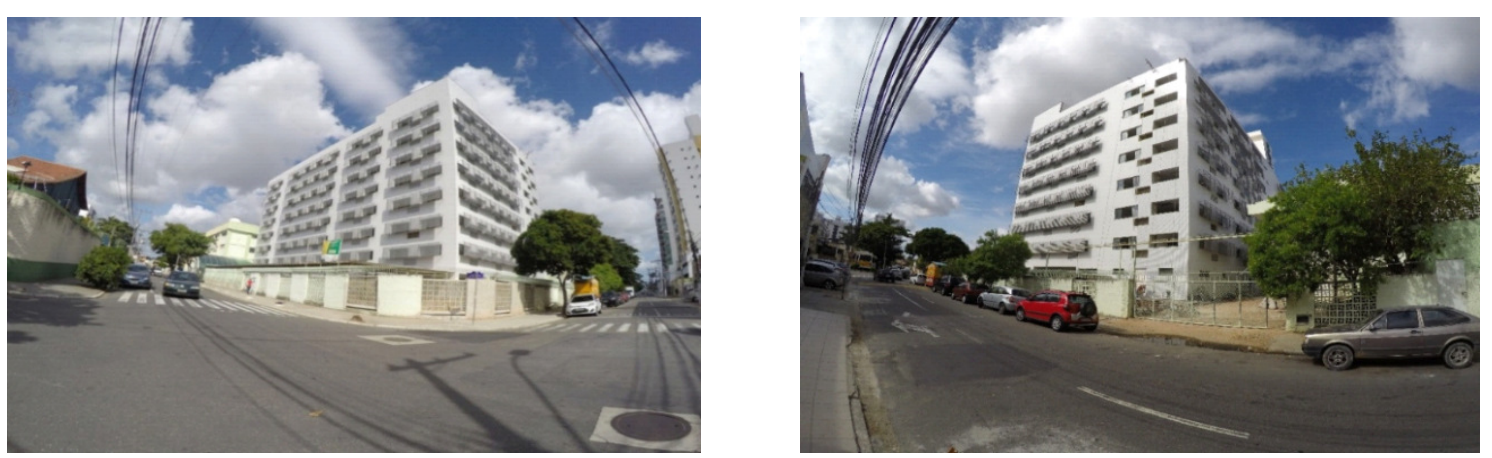

Figure 3. Study object (Block G Building)

The Block $\mathrm{G}$ consists of eight floors, being the first one, a regular volume that will house a dining hall with capacity for 252 people as well as administrative rooms, restrooms, 
vertical circulation area and labs of various courses. On the second floor, the building will have a library, study rooms, restrooms, living and circulation areas.

The other floors will house offices, mini-auditorium, laboratories and classrooms. These pavements are characterized by regular plant and volumetry, assuming a formal continuity in relation to the ground floor. The bioclimatic strategies include the use of wall masses and a lower proportion of openings (on the ground floor) as well as perforated plate bricks (other floors) as elements to protect openings from direct solar radiation.

\section{Result of the classification of the building by the conventional method}

In this stage of the work, the process of classifying the envelope of the study object was started, using the method of obtaining data practiced by the Institute's design sector. These indexes were extracted using the AutoCAD software, through manual surveys of the executive architectural design provided by the Institute's infrastructure sector. The Figure 4 represents the survey of some information necessary for classification.
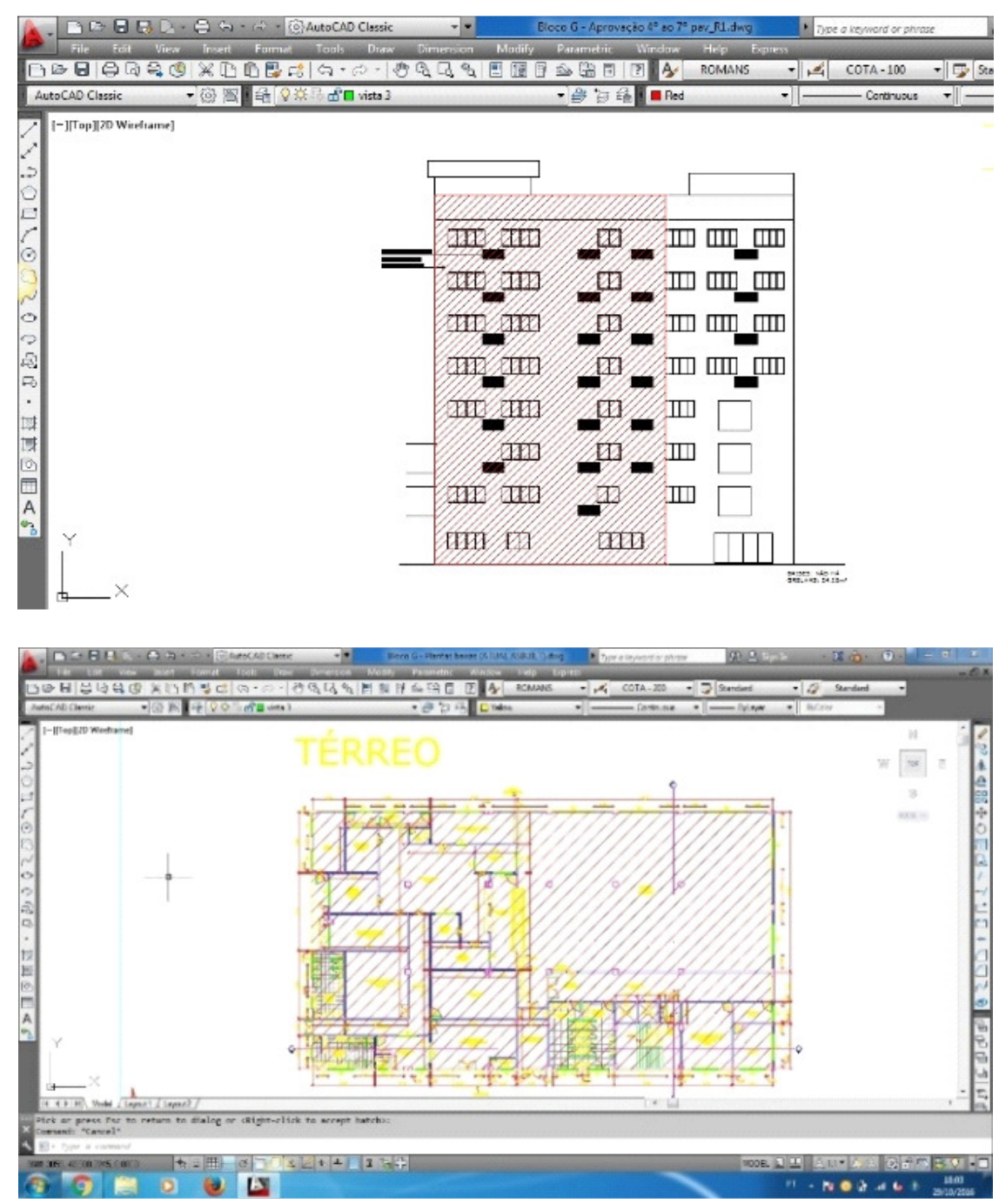

Figure 4. Mapping of some building construction parameters

After collecting data, the information collected was presented in Table 1 and Table 2 and applied in eq. (1) in the Technical Regulation of Quality for the Energy Efficiency Level of Commercial, Services and Public Buildings, used by the Brazilian government for the calculation of the consumption indicator of the federal public buildings envelope [15]. It includes the calculation parameters for buildings located in the Bioclimatic Zone 5 , with a coverage projection area $\left(A_{\mathrm{pcob}}\right)$ above $500 \mathrm{~m}^{2}$ : 
$\mathrm{IC}_{\text {env }}:-511.12 \times F A+0.92 \times F F-95.71 \times P A F_{\mathrm{t}}-99.79 \times F S-0.52 \times A V S-0.29 \times A H S-$ $380.83 \times F A \times F F+(4.27 / F F)+729.20 \times P A F_{\mathrm{t}} \times F S+77.15$

Table 1. Data of the requisites obtained for the calculation of the IC for evaluation of the envelope of the Block G Building

\begin{tabular}{cccc}
\hline \multicolumn{4}{c}{ Requirements } \\
\hline Variable & Description & Unit & Value \\
\hline$A_{\mathrm{pe}}$ & Building projection area & {$\left[\mathrm{m}^{2}\right]$} & $1,079.73$ \\
$A_{\mathrm{tot}}$ & Total building area & {$\left[\mathrm{m}^{2}\right]$} & $8,637.80$ \\
$A_{\text {env }}$ & Envelope area & {$\left[\mathrm{m}^{2}\right]$} & $4,804.56$ \\
$A V S$ & Vertical shading angle & {$\left[{ }^{\circ}\right]$} & - \\
$A H S$ & Horizontal shading angle & {$\left[{ }^{\circ}\right]$} & - \\
$F F$ & Form factor $\left(A_{\text {env }} / V_{\text {tot }}\right)$ & {$\left[\mathrm{m}^{-1}\right]$} & 0.17 \\
$F A$ & Height factor $\left(A_{\mathrm{pcob}} / A_{\mathrm{tot}}\right)$ & {$[-]$} & 0.13 \\
$F S$ & Solar factor (informed by the manufacturer $)$ & {$[-]$} & 0.47 \\
$P A F_{\mathrm{t}}$ & Percentage of opening in the total facade & {$[\%]$} & 8.8 \\
$P A F_{\mathrm{o}}$ & Percentage of opening on the west facade & {$[\%]$} & 8.65 \\
$V_{\text {tot }}$ & Total building volume & {$\left[\mathrm{m}^{3}\right]$} & $26,767.3$ \\
$\mathrm{ZB}$ & Bioclimatic zone & {$[-]$} & 5 \\
\hline
\end{tabular}

Table 2. Data of the prerequisites obtained for the calculation of the IC for evaluation of the envelope of the Block G Building

\begin{tabular}{cccc}
\hline \multicolumn{4}{c}{ Prerequisites } \\
\hline Variable & Description & Unit & Value \\
\hline$U_{\text {cob-ac }}$ & $\begin{array}{c}\text { Thermal transmittance of coverage of } \\
\text { conditioned environments }\end{array}$ & {$\left[\mathrm{W} / \mathrm{m}^{2} \mathrm{~K}\right]$} & 3.73 \\
$U_{\text {cob-anc }}$ & $\begin{array}{c}\text { Thermal transmittance of coverage of } \\
\text { unconditioned environments }\end{array}$ & {$\left[\mathrm{W} / \mathrm{m}^{2} \mathrm{~K}\right]$} & 3.73 \\
$U_{\text {par }}$ & Thermal transmittance of walls & {$\left[\mathrm{W} / \mathrm{m}^{2} \mathrm{~K}\right]$} & 2.43 \\
$A_{\text {cob }}$ & Solar coverage absorptance & {$[\%]$} & 0.8 \\
$A_{\text {par }}$ & Solar wall absorptance & {$[\%]$} & 0.2 \\
\hline
\end{tabular}

The obtained $\mathrm{IC}_{\text {env }}$ has identified that the efficiency level of the building envelope is rated "A", but according to RTQ-C, the envelope must also meet the specific prerequisites for each level of efficiency. The higher the desired level, the more restrictive are the requirements to be met. Therefore, the prerequisite for the thermal transmittance of the building coverage is higher than that required by RTQ-C for the Bioclimatic Zone 5. For this reason, the Block G Building had the final classification of the envelope as "E" (least efficient).

The software used in this method, AutoCAD, presented a very complex interface, however, insufficient for the parameterization and organization of the project information required for classification. It demonstrated limitations for obtaining structured and coordinated information, besides the difficulties in modeling complex forms.

The management of the information of this method was only possible through a few resources. In this sense, it was necessary to adopt other external project management methodologies that condensed the information into descriptive memorials, annexes and project memoranda. This process, currently in vogue in most Brazilian offices and architectural firms, is structured in a hierarchical concept of tasks, what makes it difficult 
to work in teams and to have better practices in the work processes. Therefore, the application doesn't collaborate to manage the information in the project processes.

The time of labeling through this system was composed mainly of manual processes of extraction of the parameters evaluation of the building envelope and organization of this data in other platforms (Table 3). This process was a determining factor for the time spent until the result of the label.

Table 3. Time spent in each evaluation procedure by the conventional method

\begin{tabular}{cc}
\hline Procedures performed & Time (hours) \\
\hline $\begin{array}{c}\text { Survey and registration of data concerning areas of the envelope } \\
\text { and building }\left(A U, A N C, A P T, A C, A_{\mathrm{env}}, A_{\mathrm{cob}}, A_{\mathrm{tot}}, V_{\mathrm{tot}}\right)\end{array}$ & 32 \\
$\begin{array}{c}\text { Survey and registration of data regarding the opening areas in } \\
\text { facades and coverages }\left(P A F_{\mathrm{t}}, P A F_{\mathrm{o}}\right)\end{array}$ & 16 \\
$\begin{array}{c}\quad \begin{array}{c}\text { and facades) } \\
\text { Transmittance (calculations and mapping of transmittances in the coverage }\end{array} \\
\begin{array}{c}\text { Absorptance (measurements and mapping of absorptances in the coverage } \\
\text { and facades) }\end{array}\end{array}$ & - \\
$\begin{array}{c}\text { Development of the thermal properties calculation memorial } \\
\text { (absorptance and transmittance) }\end{array}$ & - \\
$\begin{array}{c}\text { Record of the parameters considered in the evaluation } \\
\text { (filling supply spreadheets) }\end{array}$ & 16 \\
\hline Total & 96 \\
\hline
\end{tabular}

${ }^{*}$ Step whose duration has no direct relation with the accomplishment of tasks through the DXF/CAD drawings

\section{Result of the classification of the building by the proposed method}

This classification method also evaluated the Block G Building envelope individually and followed the same indexes referring to the physical characteristics of the building based on the RTQ-C. The adaptation suggested by this work was the use of BIM to optimize the data required for classification. Figure 5 summarizes the labeling process proposed in this paper.

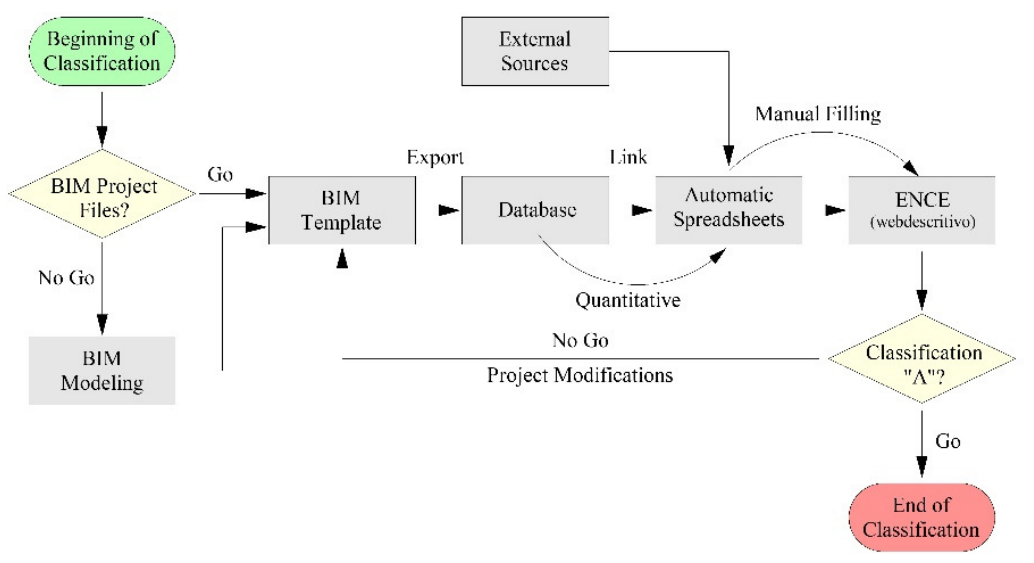

Figure 5. The labeling process proposed with the BIM concept

The evaluation process started by analyzing the project file format. The files found weren't compatible with BIM, so they had to be modeled by a software capable of communicating directly with the parameters of the BIM template. Thus, the data necessary for the labelling were exported to a database that allowed the elaboration of automatic spreadsheets. Finally, the generated data were manually inserted into the Webdescritivo online tool, created by the LabEEE with the purpose of automating the 
classification procedures established by RTQ-C, thus generating the final classification of the building.

The BIM template was created in Revit software to serve as a base file for modeling a building according to parameters required for labeling, such as wall areas, wall transmittance, glass area, $A_{\mathrm{cob}}, A_{\mathrm{pcob}}, P_{\mathrm{az}}, A_{\mathrm{tot}}$. If the studied project was developed in a BIM tool, the evaluation time would be considerably shorter, since there would be no modeling step.

The files found in the Institute's design sector were in the DWG and SKP formats and presented several information and update problems, others were not found. As the data collection didn't find any building file compatible with the created template, it was necessary to choose a BIM software and import the existing files to start building modeling (Figure 6). The software chosen was Revit. This choice was made because of the existing agreement between Autodesk and the Institute, which holds the free licenses of this software in its laboratories and administrative facilities.

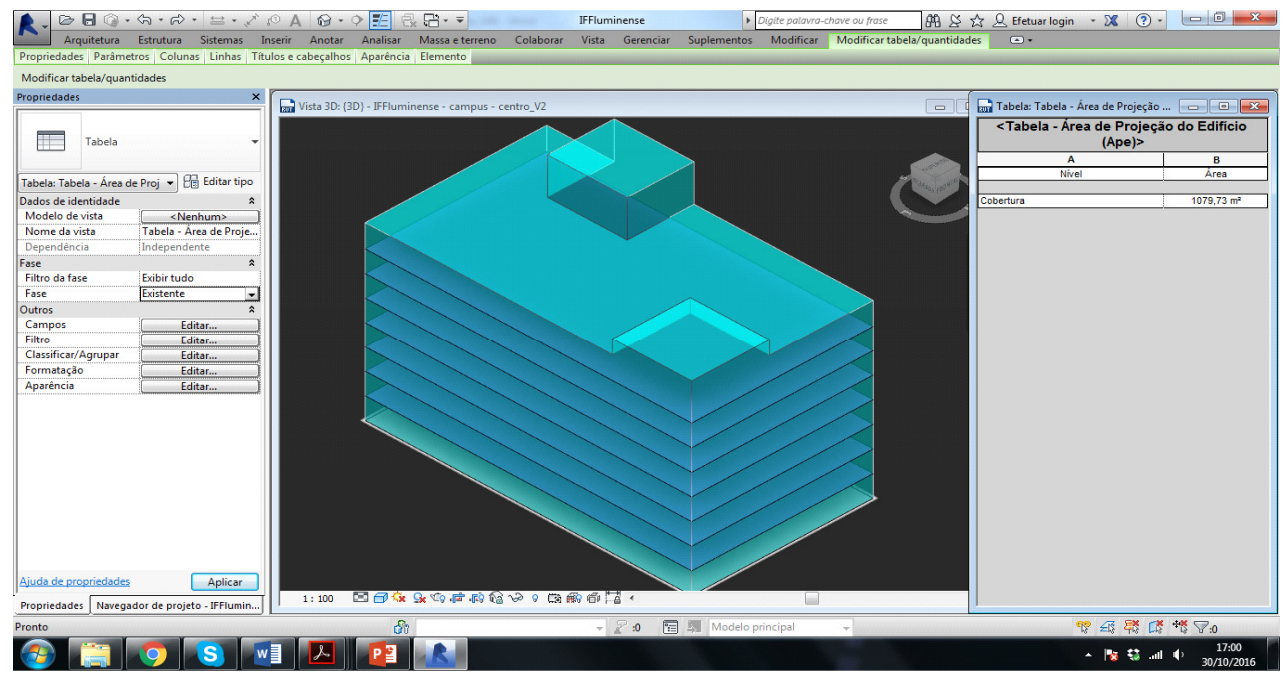

Figure 6. Block G Building model developed in Revit software

From the developed BIM model, the building requirements and prerequisites were obtained automatically through tables linked to the model. The collected data were organized and inserted in the Webdescritivo tool, as seen in Figure 7. This electronic tool assisted the process of obtaining the National Energy Conservation Label and defined the energy efficiency level of the building envelope as "E" (least efficient).

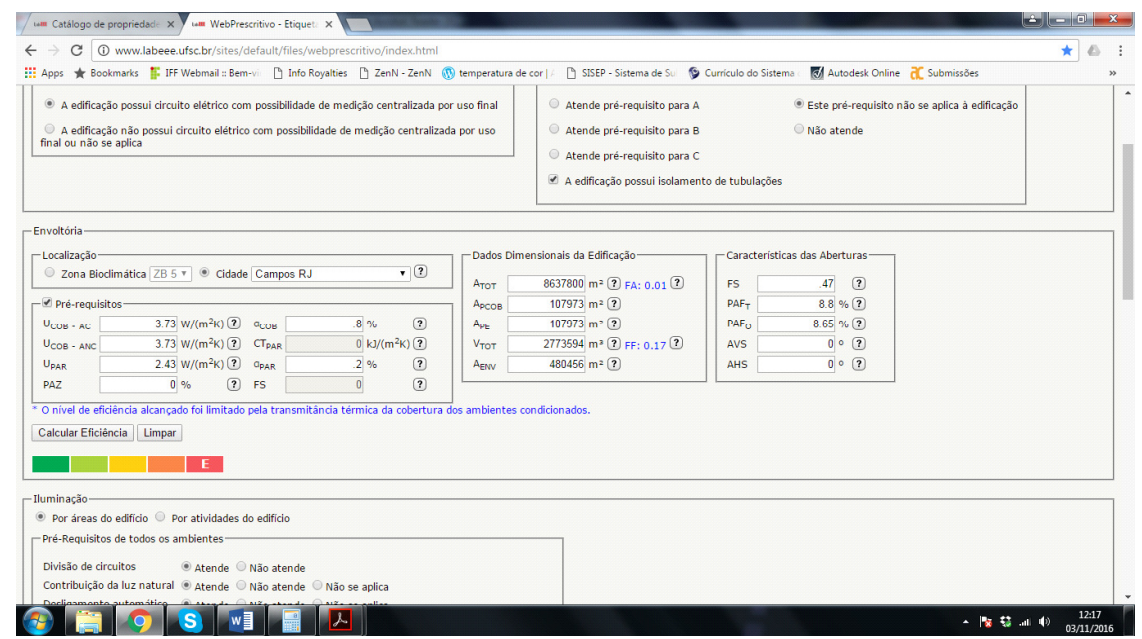

Figure 7. Result of the classification of the envelope through the Webdescritivo tool 
The result showed that the level of efficiency achieved was limited by the thermal transmittance of the coverage which presented a value higher than the established by the technical regulation. In order for the analyzed building to obtain the classification " $\mathrm{A}$ " of its envelope, according to normative instruction $\mathrm{N}^{\circ} 2 / 2014$, the coverage must be replaced by another one with a maximum thermal transmittance of $1.0 \mathrm{~W} / \mathrm{m}^{2} \mathrm{~K}$ (Figure 8 ).

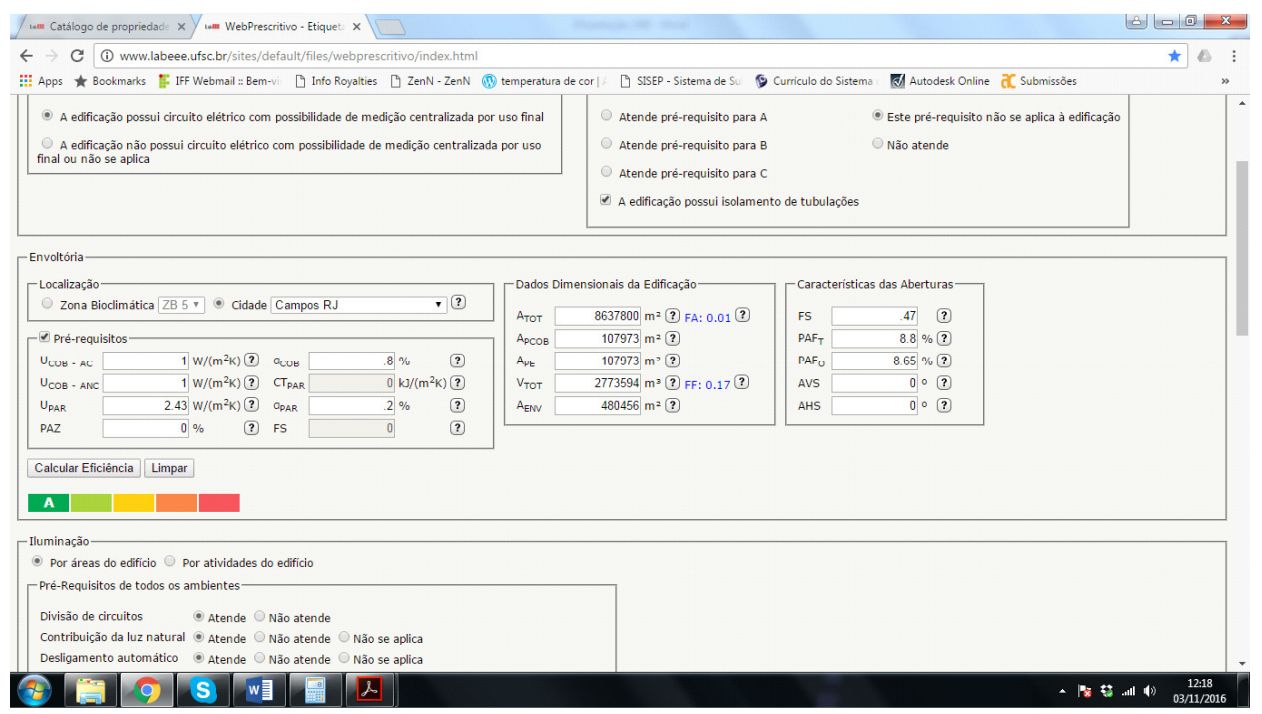

Figure 8. Simulation of the classification "A" of the Block G Building envelope with $U_{\text {cob }}$ of $1.0 \mathrm{~W} / \mathrm{m}^{2} \mathrm{~K}$

Through the analytical model of the building created by Revit, it was possible to insert all the physical characteristics of the materials in the virtual model of the building, which made possible the extraction of this information in a structured and coordinated way. The parameterization of its components helped significantly in the elaboration of quantitative elements necessary for classification.

The extraction of drawings and different quantities, obtaining automatic measurements per element and location, allowed to coordinate, generate and share design information with other computer programs through automatic processes. This platform also allowed the automatic detection of conflicts between the data and information redundancy in the survey of the design variables.

By means of this method it was possible to observe a considerable reduction in the classification time in relation to the other method (Table 4). This was largely due to the software's ability to generate and update project documentation.

Table 4. Time spent in each evaluation procedure by the conventional method

\begin{tabular}{cc}
\hline Procedures performed & Time (hours) \\
\hline $\begin{array}{c}\text { Building modeling and parameter creation } \\
\text { Survey of data concerning the areas of the building } \\
\left(A_{\mathrm{tot}}, A_{\mathrm{pcob}}, A_{\mathrm{pe}}, A_{\mathrm{env}}, P A F_{\mathrm{t}} \text { and } P A F_{\mathrm{o}}\right)\end{array}$ & 12 \\
$\begin{array}{c}\text { and absorptance of facades) } \\
\text { Building model review }\end{array}$ & $40 \mathrm{~min}$ \\
Transmittance and absorptance (calculations and mappings of transmittance & 1 \\
Manual filling into the Webdescritivo online tool & $1 \mathrm{~min}$ \\
\hline Total & $14 \mathrm{~h} \mathrm{41 \textrm {min }}$ \\
\hline
\end{tabular}

It demanded a greater time in the building modeling and the configuration of the parameters (for being more complex), but on the other hand, each configured parameter 
was automatically incorporated in the documentation. Its worth emphasizing that the creation of these parameters is only carried out once and from it, other buildings can be evaluated without this initial effort.

\section{Comparative analysis of results}

The general comparison between the two applied methods indicates that the proposed method presented a reduction of approximately $85 \%$ in the classification time, demonstrating a greater efficiency in the survey of the data of the project and in the management of the information in relation to the conventional method, which was not attractive in these aspects. Figure 9 shows the comparative analysis performed on the criterion of classification time in relation to the applied methods.

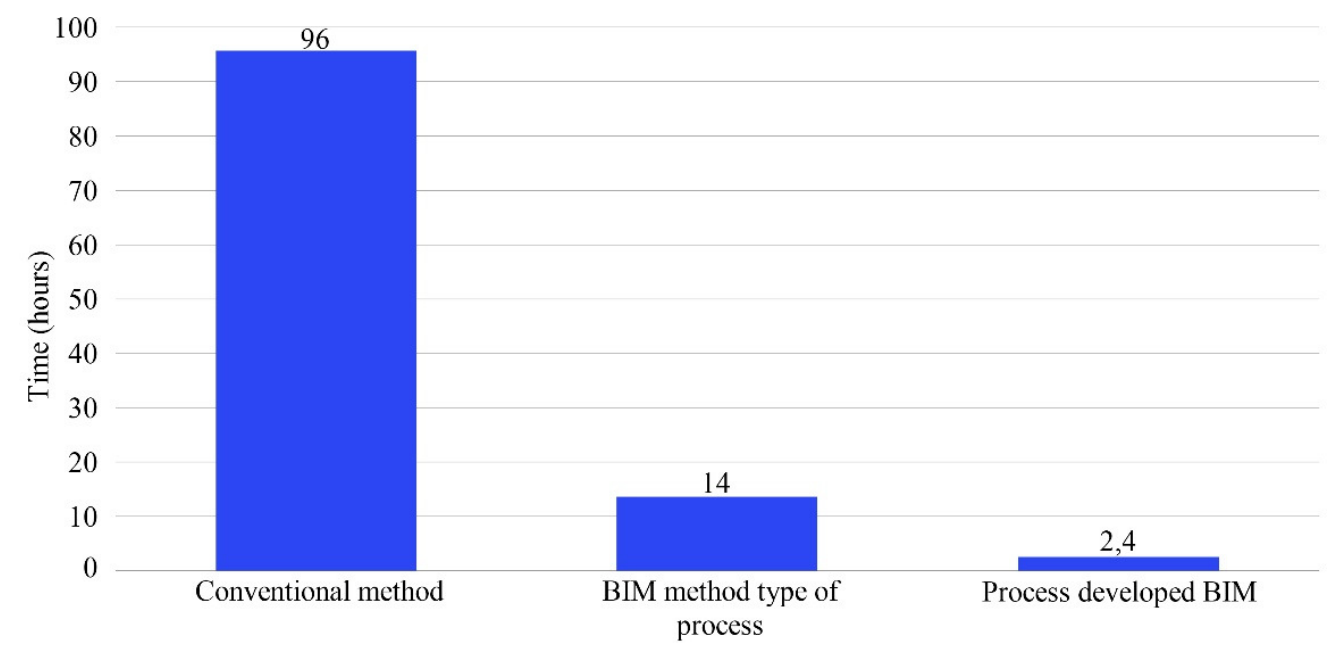

Figure 9. Comparison between the time spent in each classification process

The time spent to label the Block $G$ Building by the conventional method was estimated at 96 hours, while labeling using the BIM method can be reduced to 14 hours if the architectural design is adapted for Revit, or can be reduced to only 2 hours and 40 minutes, if it was originally developed in Revit, thus totaling a reduction of up to 40 times the time spent in the traditional method.

The first attempts to apply the prescriptive method in this building took much longer than 96 hours due to lack of documentation, doubts in the application of the method, errors, among other causes.

The phases defined in the BIM method were constituted by the modeling activities, supported by an automated process of analysis and generation of documentation that allows to modify the unique three-dimensional model so that it can reflect the result of the analysis and the development of the classification.

As pointed out by Hegger [20], this simultaneity allowed a new level of analysis and incorporation of the classification of energy efficiency into the design conception. The discussion of the formatting and the proposed solutions with all the members of the design team and the possibility of each one to interact and modify the three-dimensional model, may generate a higher quality to the final product, thus presenting greater use of resources and knowledge of the various design areas, besides the faster process classification as a whole.

The major difference in terms of phases defined in the BIM method was in relation to information flows that were no longer linear, in which the classification process didn't have to be linked to a timeline, but may occur in parallel in all stages of the process.

Likewise, the decision-making process can be anticipated and implemented through the simulation of new proposals and design solutions. And, if implanted in the Institute's 
project routine, it will eliminate any separation between the creation and classification processes, and this will constitute a novelty for the current project process.

\section{CONCLUSIONS}

The classification process carried out by the method practiced at the Institute presented several difficulties during the evaluation period. The time required for the classification of the analyzed building was high compared to the estimated time to design it. For this reason, the conventional method proves not to be feasible to be integrated into the designs routine of the Federal Fluminense Institute. The main obstacle to the application of the method mentioned above occurred because the vector drawing program, which is the AutoCAD, does not have the resources to articulate the constructive elements and the information produced for evaluation. Many activities had to be carried out manually, hampering a possible simultaneity between the project development and the energy efficiency classification of this building. In an environmental certification process, for example, in conjunction with the development of architectural design from the CAD systems, it could even be unviable due to the large amount of information to be raised, especially with each new modification of the project.

The BIM method showed advantages in several aspects. The first was the time. In the case studied, labeling could reach 2 hours and 40 minutes if the project had already been developed in some BIM software. Even considering the adaptation of the files found in AutoCAD to the Revit model, the process was performed for approximately $15 \%$ of the time of the conventional method. The time to collect the survey data by the BIM method is little changed by the size of the project, justifying its use even more. The second aspect observed was the automatic survey of the information contained in the architectural design, which is less susceptible to errors than the conventional method and the source of information is more reliable due to the parameterization of the objects. The third perceived aspect was the impact of these procedures on the way buildings are designed based on energy efficiency.

The elaboration of a BIM file model, containing the classification parameters, would facilitate future evaluations of the other Institute's buildings throughout the three main phases of the design process: preliminary studies, design and detailing. This way, the technical teams could make their decisions considering the initial results.

Hence, the present article concludes that the BIM method can actually collaborate in the support to obtain the ENCE of the studied building, since the benefits involved in the incorporation of automated documentation to the design process amplify the analysis capacity in the search of solutions and of more sustainable improvements.

\section{NOMENCLATURE}

\section{Abbreviations}

$\begin{array}{ll}\text { BIM } & \text { Building Information Modeling } \\ \text { CAD } & \text { Computer Aided Design } \\ \text { DXF } & \text { Drawing Exchange Format } \\ \text { ENCE } & \text { National Label of Energy Conservation in Buildings } \\ \text { IFF } & \text { Federal Fluminense Institute } \\ \text { LabEEE } & \text { Laboratory of Energy Efficiency of Buildings of the Federal University of } \\ & \text { Santa Catarina } \\ \text { NIBS } & \text { National Institute of Building Sciences } \\ \text { RTQ-C } & \text { Technical Quality Regulation for the Energy Efficiency Level of } \\ & \text { Commercial, Services and Public Buildings } \\ \text { ZB } & \text { Bioclimatic Zone }\end{array}$




\section{REFERENCES}

1. Bay, J.-H., Cognitive Biases in Design: The Case of Tropical Architecture, Ph.D. Thesis, TU Delft, Delft, Netherlands, 2001.

2. Venâncio, R. A., Influence of Architectural Decisions on the Energy Efficiency of Campus/UFRN (Vol. 1) (in Portuguese), Masters Dissertation, Postgraduate Program in Architecture and Urbanism, Federal University of Rio Grande Do Norte, Natal/RN, Brasil, 2007.

3. Burberry, P., Mitchell's Practical Thermal Design in Buildings, Batsfor, London, UK, 1983.

4. Lima, R. V. dos S., Design Simulation Modes: Use of Thermal Simulation Tools in the Architectural Design Process (in Portuguese), Ph.D. Thesis, Federal University of Rio Grande do Norte, Natal, Brasil, 2012.

5. Garcia, M. and Souza, R., Reflections on the Use of the Energy Efficiency Simulator in Buildings (S3E) to Evaluate the Level of Energy Efficiency in Commercial, Public and Service Buildings in Brazil (in Portuguese), Proceedings of the Encontro Nacional De Tecnologia Do Ambiente Construído, São Paulo, Brasil, 2016.

6. Clarke, J. A., Energy Simulation in Building Design, Butterworth-Heinemann, Oxford, UK, 2001.

7. Pedrini, A., Integration of Low Energy Strategies to the Early Stages of Design Process Off Office Buildings in Warm Climate, Ph.D. Thesis, University of Queensland, Brisbane, Australia, 2003.

8. Succar, B., Building Information Modelling Framework: A Research and Delivery Foundation for Industry Stakeholders, Automation in Construction, Vol. 18, No. 3, pp 357-375, 2009, https://doi.org/10.1016/j.autcon.2008.10.003

9. Martins, J. P. and Monteiro, A., Building Information Modeling (BIM), Theory and Application, 2011, http://sigarra.up.pt/flup/pt/publs_pesquisa.FormView?p_id=37013, [Accessed: 21-January-2015]

10. National Institute of Building Sciences (NIBS), National Building Information Modeling Standard, Version 1 - Part 1: Overview, Principles and Methodologies, Washington, USA, 2007.

11. Santos, E. T., Building Information Modeling (BIM): A Leap for Modernity in Information Technology Applied to Civil Construction (in Portuguese), Digital Creation, Representation and Visualization: Digital Technologies of Creation, Representation and Visualization in the Design Process ( $1^{\text {st }}$ ed.), University of Brasília, Brasília, Brasil, pp 25-62, 2012.

12. Penttilä, H., Describing the Changes in Architectural Information Technology to Understand Design Complexity and Free-Form Architectural Expression, Journal of Information Technology in Construction, Vol. 11, pp 395-408, 2006.

13. Azhar, S., Hein, M. and Sketo, B., Building Information Modeling (BIM): Benefits, Risks and Challenges, Auburn University, Auburn, Alabama, USA, 2009.

14. Normative Instruction No. 2 of June 2014, Provides for the Use of the National Energy Conservation Label (ENCE) in Projects and Respective New Federal Buildings or that Receive Retrofit, and other Measures, Brasília, Brasil, 2014.

15. National Institute of Metrology, Quality and Technology (INMETRO), Technical Requirements for Quality for Energy Efficiency Level of Commercial and Public Buildings (RTQ-C, ed.), Rio de Janeiro, Brasil, 2016.

16. Pereira Filho, Z. R., Validation of BIM in the Support to the Evaluation of the Energy Efficiency of Public Buildings (in Portuguese), Masters Dissertation, Federal University of Rio de Janeiro, Rio de Janeiro, Brasil, 2016.

17. Instituto Federal Fluminense, Institutional Development Plan 2010-2014 (in Portuguese), Campos dos Goytacazes, Essentia Editora, Rio de Janeiro, Brasil, 2011. 
18. Lamberts, R., Dutra, L. and Pereira, F., Energy Efficiency in Architecture (in Portuguese) ( $2^{\text {nd }}$ ed.), ProLivros, São Paulo, Brasil, 2004.

19. Associação Brasileira de Normas Técnicas (ABNT), NBR 15.220-3 - Thermal Performance of Buildings Part 3: Brazilian Bioclimatic Zoning and Constructive Guidelines for Single Family Dwellings of Social Interest (in Portuguese), Rio de Janeiro, Brasil, 2005.

20. Hegger, M., From Passive Utilization to Smart Solar Architecture (Schittich, C., ed.), Solar Architecture, Munique: Detail - Review of Architecture e Birkauser - Publishers of Architecture, 2003. 